\title{
Hydrocortisone release from tablets based on bioresorbable poly(ether-ester-urethane)s
}

\author{
Luis Manuel Orozco-Castellanos ${ }^{1 *}$, Angel Marcos-Fernández ${ }^{2}$, Angel Josabad Alonso-Castro ${ }^{1}$, \\ Gerardo González-García ${ }^{1}$, José Eduardo Báez-García ${ }^{1}$, Julio Cesar Rivera-Leyva ${ }^{3}$, \\ Juan Ramón Zapata-Morales ${ }^{1}$, Alan Joel Ruiz-Padilla ${ }^{1}$
}

${ }^{1}$ Division of Natural and Exact Sciences, University of Guanajuato, Guanajuato, Mexico, ${ }^{2}$ Institute of science and technology of polymers, Superior Council of Scientific Investigations, CSIC, Madrid, Spain, ${ }^{3}$ School of Pharmacy, Autonomous University of the State of Morelos, Cuernavaca, Morelos, Mexico

\begin{abstract}
Bioresorbable linear poly(ether-ester-urethane)s with different hydrophilic characteristics were synthesized from triblock copolymers of poly( $\varepsilon$-caprolactone)-poly(ethylene oxide)-poly( $\varepsilon$-caprolactone) (PCL-PEO) as macrodiols, and L-lysine diisocyanate (LDI) or hexamethylenediisocyanate (HDI) were used as the required diisocyanates. Macrodiols were obtained by ring-opening polymerization (ROP) of $\varepsilon$-caprolactone (CL). Polyurethanes were synthesized by the reaction of the triblock copolymers with LDI or HDI in solution using stannous 2-ethylhexanoate as catalyst. Polyurethane tablets were fabricated and investigated as prospective drug delivery systems. The effect of the PEO content on the polymers' performance as drug carriers was evaluated. It was found that water provoked more swelling and erosion of polymers with higher contents of PEO. The hydrocortisone release profiles were analyzed using the Ritger-Peppas approximation. An anomalous release behaviour (values of $n$ higher than 0.5) was found for most of the analyzed samples.
\end{abstract}

Uniterms: Bioresorbable polyurethanes. Drug delivery. Hydrocortisone. Macrodiol.

\section{INTRODUCTION}

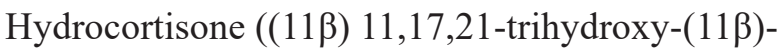
pregn-4-ene-3,20-dione) is a hydrophobic drug that is used for the treatment of certain types of cancer (leukemia, lymphoma, and multiple myelomas), allergies, and inflammation, as well as other diseases. Hydrocortisone is applied topically, orally or by intravenous injection. Nevertheless, long-term administration requires high doses of hydrocortisone, which induces side-effects such as peptic ulceration, hypokalemic alkalosis, and edema (Filipović-Grcĉić et al., 2000). To overcome theabove problems, a sustained release system should be designed to administer the drug.

Controlled drug delivery technology represents one of the most rapidly advancing areas in pharmacology. This technology requires biodegradable polymers that

\footnotetext{
*Correspondence: L. M. Orozco-Castellanos. División de Ciencias Naturales y Exactas. Universidad de Guanajuato. Noria Alta S/N, 36050 - Guanajuato, Guanajuato-México. E-mail address: orozcoz@ugto.mx
}

are metabolized or excreted by the body as non-toxic compounds. Such systems offer numerous advantages compared to conventional dosage forms, including reduced dosing requirements, improved efficacy, and reduced toxicity (Deng et al., 1999; Deng et al., 2001; Park, Kim, Kim, 2005; Mohamadnia et al., 2009). Controlled release can be achieved by using various devices, for example mechanical pumps, osmotic pumps, diffusion-controlled systems containing reservoirs, or matrix systems, and chemically controlled systems composed of biodegradable or non-biodegradable polymers, among others (Park, Kim, Kim, 2005).

Some of the biodegradable materials include: poly(ethylene oxide) (PEO), polyurethanes (PUs), and poly ( $\varepsilon$-caprolactone) (PCL), among others, which can self-disperse in certain solvents and behave as a good solvent for one block and as a poor solvent for the other, which permits the formation of nonionic micelles (Abraham, Marcos-Fernández, Román, 2006). PUs, which are commonly made by reacting hydroxyl-terminated polyesters or polyethers with polyisocyanates, are 
considered excellent biomedical materials based on their good chemical stability, mechanical flexibility and their excellent blood compatibility (Cherng et al., 2013). PEO, which is used as the hydrophilic block in the copolymers, has been widely used to improve the biocompatibility of materials that contact the blood (Storey, Wiggins, Puckett, 1994; Deng et al., 1999). PCL, used as the hydrophobic block, is a biodegradable and biocompatible polymer that has been used in various biomedical applications because of its excellent biocompatibility and degradability (Bogdanov et al., 1999). Some authors have reported the use of PUs-based tablets containing 7-tertbutyldimethylsilyl-10-hydroxy-camptothecin (Sivak et al., 2008), anhydrous theophylline (Campiñez et al., 2013), diprophylline (Claeyes et al., 2014), and metformin hydrochloride (Verstraete et al., 2016). These studies suggested that PUs increases drug release.

This study reports the synthesis of PUs with different contents (30 and $40 \mathrm{~mol} \%$ ) and molecular weight ( 900 and $\left.2000 \mathrm{~g} \cdot \mathrm{mol}^{-1}\right)$ of PEO. Tablets based on PEO-containing PUs were filled with hydrocortisone $(1 \% \mathrm{w} / \mathrm{w})$, mixed in solution, and molded from the soluble form and tested for drug delivery. In vitro matrix water uptake profiles were obtained by measuring the tablets' weight increase. The in vitro hydrocortisone release profiles from the polyurethane tablets were also investigated. The results are discussed in terms of the PEO content. To our knowledge, there are no reports regarding the performance of amino acid-based polyurethanes as drug delivery carriers.

\section{MATERIAL AND METHODS}

\section{Chemicals and reagents}

Hexamethylene-diisocyanate (HDI), stannous 2-ethylhexanoate, and 1,2-dichloroethane (DCE) were obtained from Sigma-Aldrich (St. Louis, MO). PEO diols (Sigma-Aldrich) with number-average molecular weights $\left(M_{n}\right)$ of 900 and $2000 \mathrm{~g} \cdot \mathrm{mol}^{-1}$ were dried under vacuum at $90^{\circ} \mathrm{C}$ for at least $6 \mathrm{~h}$ on a rotary evaporator before use. DCE was distilled over phosphorous pentoxide before its use. $\varepsilon$-Caprolactone ( $\varepsilon$-CL) was obtained from Merck (Schuchardt, Germany) and used as received. L-Lysinediisocyanate (methyl 2,6-diisocyanatohexanoate)(LDI) was donated by Kyowa Hakko Co. Ltd, Japan.

\section{Synthesis of poly(ester-ether-ester) macrodiols}

Triblock copolymers (PCL-PEO-PCL) with different hydrophilic-to-hydrophobic ratios were synthesized by using the following procedure (Cerrai et al., 1994):
$\varepsilon$-CL and the corresponding amount of PEO were placed into a three-necked flask. Stannous 2-ethylhexanoate ( $0.1 \%$ weight with respect to the monomer) was added. Polymerization was carried out in bulk for $2 \mathrm{~h}$ with magnetic stirring at $130^{\circ} \mathrm{C}$. The final product (macrodiol) was exhaustively dried under high vacuum $\left(10^{-3} \mathrm{~mm} \mathrm{Hg}\right)$ while cooling for $24 \mathrm{~h}$ at room temperature and stored under vacuum until used. All reaction yields were higher than $95 \%$.

\section{Synthesis of poly(ether-ester-urethane)s (PEEUs)}

To control the final molecular weight of the PEEUs, a nonstoichiometric monomer ratio was used (Li et al., 2009). The effect of stoichiometric imbalance on the final molecular weight was investigated in the polymerization reaction between LDI and commercial PCL-diol $\left(M_{\mathrm{n}}=1250\right)$. A catalyst concentration of $0.2 \%$ $\mathrm{w} / \mathrm{w}$ was used. It was determined that the diisocyanate/ macrodiol molar ratio that produced the highest final molecular weight was 1.05:1. To obtain the PEEUs, polymerization was performed in DCE solution by mixing the diisocyanate and the macrodiol in 1.05:1 molar ratio at $85^{\circ} \mathrm{C}$ with magnetic stirring under a nitrogen atmosphere for two hours. The molar concentration $(0.39 M)$ was selected to have less than $100 \%$ total w/v (polymer/ solvent). The resulting polymer was exhaustively dried under vacuum for complete solvent removal.

\section{Characterization}

Proton nuclear magnetic resonance ( ${ }^{1} \mathrm{H}$ NMR) spectra were acquired using a Varian XLR-300 NMR spectrometer operating at $300 \mathrm{MHz}$. The ${ }^{1} \mathrm{H}$ NMR spectra were obtained from $5 \% \mathrm{w} / \mathrm{v} \mathrm{CDCl}_{3}$ solutions at room temperature. The spectra were referenced to the residual solvent protons at $\delta 7.26$ for $\mathrm{CDCl}_{3}$.

Differential scanning calorimetry (DSC) experiments were carried out in a Mettler Toledo (DSC822e) calorimeter under nitrogen purge. Samples weighing between 5 and $15 \mathrm{mg}$ were sealed in aluminum pans. Two scans were performed using a $10{ }^{\circ} \mathrm{C} \mathrm{min}-1$ heating rate, the first from ambient temperature to $80{ }^{\circ} \mathrm{C}$ and the second from -90 ${ }^{\circ} \mathrm{C}$ to $80^{\circ} \mathrm{C}$. In both cases, the fastest cooling rate of the instrument was used between runs.

The gel permeation chromatography-multi angle light scattering (GPC-MALLS) spectra were determined with a MALLS Dawn Eos F laser photometer using the ASTRA v 4.70 software (Wyatt Technology Corp., Santa Barbara, CA). A laser wavelength of $690 \mathrm{~nm}$ was used. For the analysis, a set of TSK Gel G 3000 HHR and G 
6000 HHR columns were employed, and THF was used as eluent.

\section{Preparation of PUs tablets}

The PUs were placed in molds, melted at $60{ }^{\circ} \mathrm{C}$, and solidified in a freezer to yield tablets of $7 \mathrm{~mm}$ diameter and $1.5 \mathrm{~mm}$ thickness. Their final weights were in the range of 45 to $55 \mathrm{mg}$.

\section{Tablets containing $1 \%$ hydrocortisone $(w / w)$ preparation}

PUs were mixed with an acetone solution containing $1 \%(\mathrm{w} / \mathrm{w})$ hydrocortisone, and the solution was dried at $60{ }^{\circ} \mathrm{C}$ under vacuum. The molten solids were placed in a mold and solidified in a freezer to yield tablets of $7 \mathrm{~mm}$ diameter and $1.5 \mathrm{~mm}$ thickness. Their final weights were in the range of 45 to $55 \mathrm{mg}$.

\section{In vitro release studies}

The release of hydrocortisone was evaluated using UV-vis spectroscopy (Orozco-Castellanos, MarcosFernández, Martínez-Richa, 2009). Tablets of un-filled and filled PUs were placed in vials with $15 \mathrm{ml}$ of $0.1 \mathrm{M}$ aqueous citrate buffer at $\mathrm{pH} 5.0$ or $0.1 \mathrm{M}$ aqueous phosphate buffer at $\mathrm{pH} 7.4$ (both containing $0.05 \% \mathrm{w} / \mathrm{v}$ sodium azide as a preserving agent) in an incubator at $37^{\circ} \mathrm{C}$. Aliquots of the upper layer $(3.0 \mathrm{ml})$ were used for UV-vis analysis of the hydrocortisone concentration using an Agilent 8453 UV-vis spectrophotometer (Agilent, Germany) at $248 \mathrm{~nm}$. After analysis, the samples were returned to the original solution. Three runs were performed for each condition tested.

\section{Swelling and erosion studies}

The tablets (ranging from 40 to $60 \mathrm{mg}$ ) were immersed in $15 \mathrm{~mL}$ of phosphate buffer solution ( $\mathrm{pH}$ 7.4) at $37^{\circ} \mathrm{C}$. Thereafter, the tablets were removed from the solution at specific time intervals, wiped with filter paper, and then weighed immediately. The Water Uptake (WU) of the sample was calculated using the following expression (Abraham, Marcos-Fernández, Román, 2006; Dai et al., 2008): $\mathrm{WU}(\%)=\left[\left(\mathrm{W}-\mathrm{W}_{0}\right) / \mathrm{W}_{0}\right] \times 100$, where $\mathrm{W}$ is the weight of the swollen tablets and $\mathrm{W}_{0}$ is the initial weight of the tablets.

Erosion was evaluated 10 days after the start of the experiments. At that time, the tablets from the swelling study were removed from the falcon tubes, dried in an oven at $37 \pm 0.5^{\circ} \mathrm{C}$ overnight, and then weighed after cooling to room temperature in a desiccator. The degree of erosion was calculated using the following formula (Caffagi et al., 2005): Matrix erosion $(\%)=\left(W_{1}-W_{3}\right) / W_{1} \times 100$, where $W_{3}$ was the weight of dried slabs and $W_{1}$ was the initial weight. The results are reported as the means of three determinations.

\section{RESULTS}

\section{Synthesis and characterization of PEEUs}

The list of the obtained polyurethanes can be found in Table I. The structure of the HO-PCL- $b$-PEO$b$-PCL-OH triblocks was characterized by ${ }^{1} \mathrm{H}$ NMR. The methylene group adjacent to the hydroxyl terminal group $\left(-\mathrm{CH}_{2} \mathrm{OH}\right)$ for PCL appeared as a triplet at 3.62 ppm, which completely overlapped with the signals attributed to the PEO main chain $\left[-\left(\mathrm{CH}_{2}-\mathrm{CH}_{2}-\mathrm{O}\right)_{\mathrm{n}}-\right]$. To visualize the end-groups in the PCL block, hydroxyl terminal groups in HO-PCL- $b$-EO- $b$-PCL-OH were derivatized with trifluoroacetic anhydride (TFAA), which produced a trifluoroacetate end group $\left(-\mathrm{CH}_{2} \mathrm{O}(\mathrm{C}=\mathrm{O}) \mathrm{CF}_{3}\right)$, which produced a signal at $4.3 \mathrm{ppm}$ that corroborated their chemical nature. The preparation of PEEUs was carried out by step-wise polymerization of HO-PCL$b$-EO- $b$-PCL-OH with L-lysine diisocyanate (LDI) or hexamethylenediisocyanate, (HDI) using $\mathrm{Sn}(\mathrm{Oct})_{2}$ as a catalyst. After the polymerization reaction, a series of PEEUs with different contents of PEO (TABLE I) were obtained (30-40 wt. \%).

The thermal properties in the PEEUs were studied using differential scanning calorimetry (DSC) (Table I). These results showed a series of endothermic peaks $\left(T_{\mathrm{m}}\right)$ that were mainly attributed to the fusion of PCL blocks in the PEEUs.

\section{Kinetics and mechanism of hydrocortisone release}

The results of the hydrocortisone release study are reported in terms of percent hydrocortisone release and were calculated considering the entire time interval of the test, $0-200 \mathrm{~h}$. The release curves are shown in Figure 1.

The kinetics and the release mechanisms can be evaluated using the following equation (Ritger, Peppas, 1987a,b; Cafaggi et al., 2005):

$$
M_{t} / M_{\infty}=k t^{n}
$$

where $M_{t} / M_{\infty}$ is the hydrocortisone fraction at time $t, k$ 
TABLE I - Number-average molecular weight $\left(M_{n}\right)$, weight-average molecular weight $\left(M_{w}\right)$ and thermal properties of the synthesized PEEUs

\begin{tabular}{lcccccc}
\hline Polyurethane & $M_{n}{ }^{\mathrm{a}}$ & $M_{w}{ }^{\mathrm{a}}$ & $\mathrm{PI}^{\mathrm{a}}$ & $T_{\mathrm{m}}\left({ }^{\circ} \mathrm{C}\right)^{\mathrm{b}}$ & $\Delta H_{m}{ }^{\mathrm{c}}(\mathrm{J} / \mathrm{g})$ & $x_{\mathrm{i}}{ }^{\mathrm{d}}$ \\
\hline $900-30-S n-L D I$ & 34610 & 41710 & 1.25 & 34,41 & 44.6 & 32 \\
900-30-Sn-HDI & 45520 & 47580 & 1.04 & 37,43 & 44.2 & 32 \\
2000-30-Sn-HDI & 35650 & 38050 & 1.06 & $44,49,61$ & 67.3 & 49 \\
2000-30-Sn-LDI & 39100 & 60740 & 1.55 & $36,42,48$ & 67.4 & 49 \\
2000-40-Sn-LDI & 34130 & 35290 & 1.03 & $21,40,45$ & 66.6 & 49 \\
2000-40-Sn-HDI & 30770 & 39850 & 1.29 & 16,42 & 61.9 & 45 \\
\hline
\end{tabular}

${ }^{a}$ Obtained by GPC-MAALS; P.I. $=$ Polydispersity index: $M_{w} / M_{n}{ }^{\text {b }}$ Obtained from the first heating scan by DSC. ${ }^{\mathrm{c}}$ Total area under the endothermic melting peaks. ${ }^{\mathrm{d}}$ Crystallinity $\left(x_{\mathrm{i}}\right)$ of PCL in the PEEUs.

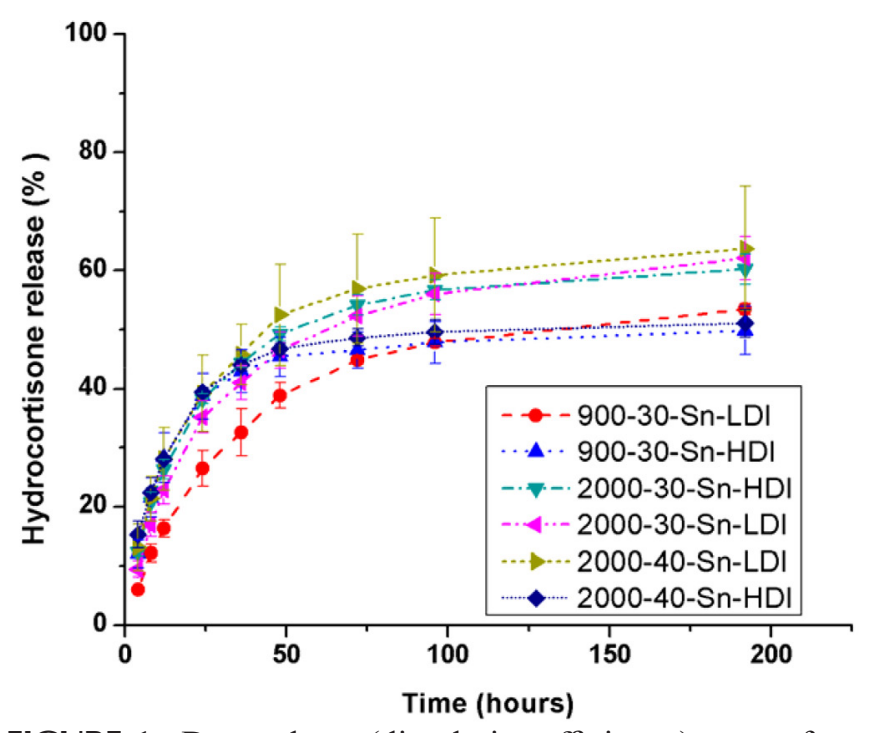

FIGURE 1 - Drug release (dissolution efficiency) curves from tablets of polyurethanes with $1 \%(\mathrm{w} / \mathrm{w})$ hydrocortisone in phosphate buffer at $\mathrm{pH} 7.4$ and $37^{\circ} \mathrm{C}$.

is a proportionality constant that accounts for the matrix characteristics, and $n$ is an exponent whose value is indicative of the drug-release mechanism. The equation is valid only if data points covering up to $60 \%$ of the released hydrocortisone are considered.

In a logarithmic representation, $\log k$ and $n$ are obtained as the intercept and slope, respectively. The values of $k$ and $n$ obtained from the curves characteristic of the different matrices are reported in Table II. The results show that the $n$ values varied from 0.55 to 0.78 .

\section{Swelling and erosion studies}

Water uptake by the matrices and their erosion behavior can be evaluated from the curve profiles shown in Figure 2 and from gravimetric data, respectively. The PUs with a higher content of hydrophilic soft segments
TABLE II - Values for $k$ and $n$ ( $\pm 95 \%$ confidence intervals) obtained by log plot of hydrocortisone release curves from tablets of different compositions at $\mathrm{pH}$ 7.4. $R^{2}$ values are also reported

\begin{tabular}{lccc}
\hline Matrix & $\boldsymbol{k}$ & $\boldsymbol{n}$ & $\boldsymbol{R}^{\mathbf{2}}$ \\
\hline 900-30-Sn-LDI & 0.042 & 0.759 & 0.985 \\
900-30-Sn-HDI & 0.080 & 0.789 & 0.996 \\
2000-30-Sn-LDI & 0.079 & 0.693 & 0.996 \\
2000-30-Sn-HDI & 0.057 & 0.731 & 0.994 \\
2000-40-Sn-LDI & 0.076 & 0.707 & 0.999 \\
2000-40-Sn-HDI & 0.139 & 0.551 & 0.999 \\
\hline
\end{tabular}

(polyethylene glycol, PEG) exhibited an increased water uptake as well as a faster degradation rate compared to the PUs with a higher content of hydrophobic soft segments (PCL) (Table III).

In the hydrolytic stability study, weight-loss measurements were very difficult to achieve because the hydrophilic nature of the PEO segment precluded the complete drying of samples. At the end of the experiment, the 900-30 PUs lost between 1.8 and $4.0 \%$ of their initial weight, whereas the 2000-30 PUs degraded more slowly, retaining approximately $99.5 \%$ of their initial weight. The 2000-40-Sn-LDI and the 2000-40-Sn-HDI PUs exhibited a higher weight loss (5.5 and 5.9\%, respectively) (Table III).

\section{DISCUSSION}

The macrodiols, which are precursors of the synthesis of PEEUs, are triblock copolymers derived from $\alpha, \omega$-hydroxytelechelic poly( $\varepsilon$-caprolactone- $b$-ethylene oxide- $b$ - $\varepsilon$-caprolactone) (HO-PCL- $b$-PEO- $b$-PCL-OH) that obtained by ring-opening polymerization (ROP) of $\varepsilon$-caprolactone (CL) in presence of $\alpha, \omega$-hydroxytelechelic poly(ethylene oxide) (PEO) and tin octoate $\left(\mathrm{Sn}(\mathrm{Oct})_{2}\right)$ as 


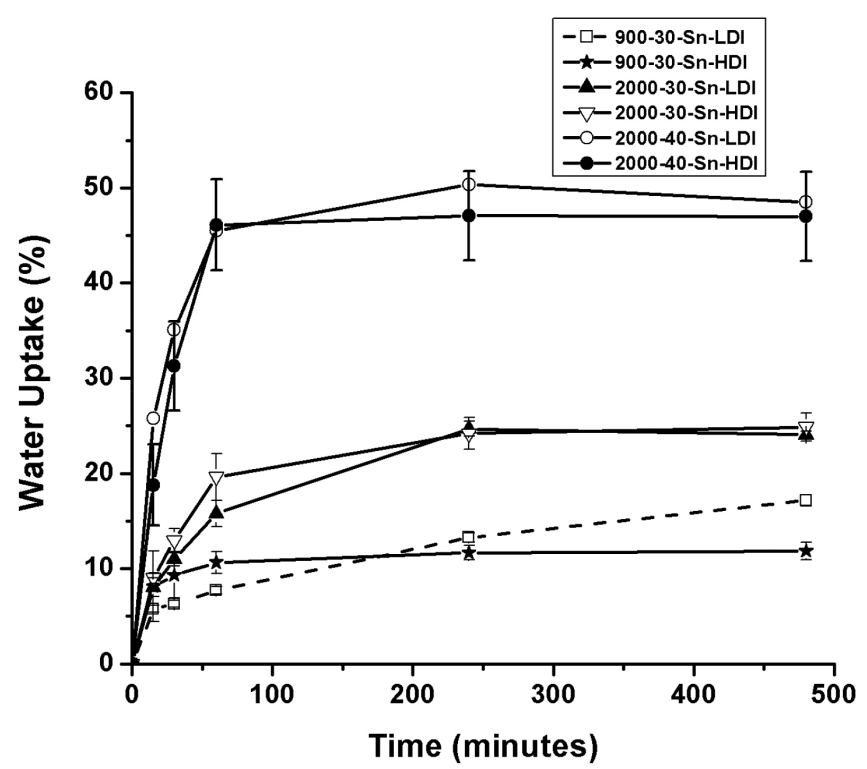

FIGURE 2 - Swelling characteristics of dry slabs in phosphate buffer ( $\mathrm{pH} 7.4)$ at $37^{\circ} \mathrm{C}$.

TABLE III - Water uptake, erosion percent, and dissolution efficiency of polyurethane tablets

\begin{tabular}{lccc}
\hline Polyurethane & $\begin{array}{c}\text { Maximum } \\
\text { water } \\
\text { uptake (\%) }\end{array}$ & $\begin{array}{c}\text { Matrix } \\
\text { erosion } \\
\mathbf{( \% )}^{\mathbf{c}}\end{array}$ & $\begin{array}{c}\text { Dissolution } \\
\text { efficiency }^{\mathbf{a}, \mathbf{b}}\end{array}$ \\
\hline 900-30-Sn-LDI & 17.1 & 1.83 & 53.4 \\
900-30-Sn-HDI & 11.8 & 4.08 & 49.8 \\
2000-30-Sn-HDI & 24.8 & 0.42 & 49.8 \\
2000-30-Sn-LDI & 24.0 & 0.46 & 62.1 \\
2000-40-Sn-LDI & 48.5 & 5.53 & 63.7 \\
2000-40-Sn-HDI & 47.0 & 5.90 & 51.0 \\
\hline
\end{tabular}

aDefined as the area under the dissolution curve up to $192 \mathrm{~h}$, expressed as a percentage of the area of the rectangle described by $100 \%$ dissolution in the same time. ${ }^{b} n=3$, pooled S.D. $=4.7$ $(\%) .{ }^{\mathrm{c}} n=3$, pooled S.D. $=1.1(\%)$

initiator and catalyst, respectively. Abraham, MarcosFernández, Román (2006) reported that when the content of PCL (70-60 wt.\%) is higher than the content of PEO (30-40 wt.\%) the endothermic peaks can be attributed primarily to crystalline domains of PCL. The crystallinity $\left(x_{\mathrm{i}}\right.$, Table I) was similar for PEEUs produced using either diisocyanate, LDI or HDI. Thus, the crystallinity was independent of the diisocyanate type. The number-average molecular weights $\left(M_{\mathrm{n}}\right)$ for PEEUs were obtained by GPCMALLS and demonstrated a range from 25000 to 39000 $\mathrm{Da}$. These values are convenient for the manufacture of PEEU films (Abraham, Marcos-Fernández, Román, 2006). In addition, the ${ }^{1} \mathrm{H}$ NMR information obtained in this study corroborates the data from a previous study (Abraham, Marcos-Fernández, Román, 2006).

Using the criteria assumed for the evaluation of drug-release data from swelling systems (Ritger, Peppas, 1987b), the calculated values for the prepared materials suggested that the release mechanism could be considered to be generally non-Fickian (Higuchi type of release) (Siepmann, Siepmann, 2012), although some the values were close to the Fickian limit of $n=0.5$. Under these conditions, the hydrocortisone diffuses partially through the swollen matrix and partially through the hydrated expanding matrix. The mechanism for the release therefore became increasingly diffusion-mediated. This process is essentially as would be expected for a hydrophobic drug such as hydrocortisone, which is mainly entrapped in the hydrophobic-rich zones of the polymer. Based on the $k$ values, which were generally moderate, the results indicated the presence of a moderate burst effect for all matrices. The release of drugs that are dispersed in (and not covalently bound to) PU matrices is dependent on the level of drug loading and the solubility of the drug in the matrix as well as the degradation rate and swelling of the matrices (Johnson et al. 2010).

The swelling extent is represented by the maximum water uptake, as shown by the corresponding curves. For all the samples, the time to reach the steady-state or the water uptake was approximately $50 \mathrm{~min}$. At longer times, the values remained almost constant for the next 8 hours. The results clearly show that the equilibrium values decrease with increasing PCL content. Therefore, materials with higher PEO content, which are more hydrophilic, are expected to display higher water contents at equilibrium. Thus, 2000-40-Sn-LDI and 900-30-Sn-HDI, which have different hydrophilicity, exhibited the highest and lowest water uptake values; 48.5 and $11.8 \%$, respectively. As expected, there was a direct relationship between ethylene oxide (EO) unit content and water uptake. The 2000-40-Sn-LDI and 2000-40-Sn-HDI samples exhibited a higher weight loss (5.5 and 5.9\%, respectively). PUs are susceptible to biodegradation principally as the result of cleavage of hydrolytically sensitive bonds present in their soft segments. PUs with amorphous soft segments have been reported to degrade more rapidly than those with semi-crystalline soft segments (Skarja, Woodhouse, 1998). Furthermore, a higher proportion of hard segments resulted in a lower rate of hydrolytic degradation because the crystallinity was higher than the water absorption (Campos et al., 2011). Moreover, an increase in the molecular weight of the PCL was associated with an increase in the crystallinity of the soft segments that in turn resulted in a decrease in the water uptake (Reddy 
et al., 2010). It was observed that the swelling rates for the samples studied herein increased with increases in the PEO content. The isocyanate moiety used (HDI or LDI) did not affect the swelling behavior. In other carriers for drug delivery, such as hydrophobic carriers that are used for hydrophobic drug delivery, it has been reported that the drug release might not be controlled by the carrier. Furthermore, some toxicity of these materials has been observed (Cabanes et al., 1998). In addition, the hydrophobic carriers used for hydrophobic drug delivery absorb less water and subsequently degrade more slowly (Makadia, Siegl, 2011). Therefore, polyurethane-based drug delivery could have some advantages compared to hydrophobic carriers.

\section{CONCLUSIONS}

The observed release behavior indicated that the PEEUs studied in this paper have a potential use as delivery carriers for hydrophobic drugs. The 900-30 PUs were the best option for hydrocortisone delivery. Further studies are being carried out in our laboratory to provide a better characterization of hydrocortisone administration using these materials.

\section{ACKNOWLEDGMENTS}

We acknowledge the financial support provided by the Consejo Nacional de Ciencia y Tecnología (CONACYT), México, Ministerio de Ciencia e Innovación (MAT2014-52644-R), Spain, and the Universidad de Guanajuato, México. Authors are indebted to Dr. Guillermo Mendoza-Diaz (Universidad de Guanajuato) for his helpful discussions. The authors thank Salvador López Morales (Instituto de Investigaciones en Materiales, UNAM) for GPC-MALLS analysis. The authors wish to thank the Directorate for Research Support and Postgraduate Programs at the University of Guanajuato for their support in the editing of the English-language version of this article.

\section{REFERENCES}

ABRAHAM, G.A.; MARCOS-FERNÁNDEZ, A.; ROMÁN, J.S. Biresorbable poly(ester-ether urethane)s from L-Lysine diisocyanate and triblock copolymers with different hydrophilic character. J. Biomed. Mater. Res. A., v.76, n.4, p.729-736, 2006.
BOGDANOV, B.; TONCHEVA, V.; SCHACHT, E.; FINELLI, L.; SARTI, B.; SCANDOLA, M. Physical properties of poly(ester-urethanes) prepared from different molar mass polycaprolactone-diols. Polymer v.40, n.11, p.3171-3182, 1999.

CABANES, A.; BRIGGS, K.E.; GOKHALE, P.C.; TREAT, J.A.; RAHMAN, A. Comparative in vivo studies with paclitaxel and liposome-encapsulated paclitaxel. Int. J. Oncol., v.12, n.5, p.1035-1040, 1998.

CAFAGGI, S.; LEARDI, R.; PARODI, B.; CAVIGLIOLI, G.; RUSSO, E.; BIGNARDI, G. Preparation and evaluation of a chitosan salt-polaxamer 407 based matrix for buccal drug delivery. J. Control. Release, v.102, n.1, p.159-169, 2005.

CAMPIÑEZ, M.D.; AGUILAR-DE-LEYVA, Á.; FERRIS, C.; DE PAZ, M.V.; GALBIS, J.A.; CARABALLO, I. Study of the properties of the new biodegradable polyurethane PU (TEG-HMDI) as matrix forming excipient for controlled drug delivery. Drug Dev. Ind. Pharm., v.39, n.11, p.17581764, 2013.

CAMPOS, E.; CORDEIRO, R.; SANTOS, A.C.; MATOS, C.; GIL, M.H. Design and characterization of bi-soft segmented polyurethane microparticles for biomedical application. Colloids Surf., B, v.88, n.1, p.477-482, 2011.

CERRAI, P.; GUERRA, G.D.; LELLI, L.; TRICOLI, M.; DEL GUERRA, R.S.; CASCONE, M.; GIUSTI, P. Poly(esterether-ester) block copolymers as biomaterials. J. Mater. Sci. Mater. Med., v.5, n.1, p.33-39, 1994.

CHERNG, J.Y.; HOU, T.Y.; SHIH, M.F.; TALSMA, H.; HENNINK, W.E. Polyurethane based drug-delivery systems. Int. J. Pharm., v.450, n.1/2, p.145-162, 2013.

CLAEYS, B.; DE BRUYN, S.; HANSEN, L.; DE BEER, T.; REMON, J.P.; VERVAET, C. Release characteristics of polyurethane tablets containing dicarboxylic acids as release modifiers: a case study with diprophylline. Int. J. Pharm., v.477, n.1/2, p.244-250, 2014.

DAI, Y.N.; LI, P.; ZHANG, J.P.; WANG, A.Q.; WEI, Q. Swelling characteristics and drug delivery properties of nifedipine-loaded $\mathrm{pH}$ sensitive alginate-chitosan hydrogel beads. J. Biomed. Mater. Res. B Appl. Biomater, v.86, n.2, p.493-500, 2008. 
DENG, X.M.; LI, X.H.; YUAN, M.L.; XIONG, C.D.; HUANG, Z.T.; JIA, W.X.; ZHANG, Y.H. Optimization of preparative conditions for poly-DL-Lactide-polyethylene glycol microspheres with entrapped Vibrio cholera antigens. J. Control. Release, v.58, n.2, p.123-131, 1999.

DENG, X.; ZHOU, S.; LI, X.; ZHAO, J.; YUAN, M. In vitro degradation and release profiles for poly-dl-lactidepoly(ethylene glycol) microspheres containing human serum albumin. J. Control. Release, v.71, n.2, p.165-173, 2001 .

FILIPOVIĆ-GRCĈIĆ, J.;VOINOVICH, D.; MONEGHINI, M.; BEĆIREVIĆ-LAĆAN, M.; MAGAROTTO, L.; JALSENJAK, I. Chitosan microspheres with hydrocortisone and hydrocortisone-hydroxypropylbcyclodextrin inclusion complex. Eur. J. Pharm. Sci., v.9, n.4, p.373-379, 2000.

JOHNSON, T.J.; GUPTA, K.M.; FABIAN, J.; ALBRIGHT, T.H.; KISER, P.F. Segmented polyurethane intravaginal rings for the sustained combined delivery of antiretroviral agents dapivirine and tenofovir. Eur. J. Pharm. Sci., v.39, n.4, p.203-212, 2010.

LI, Z.; YANG, X.; WU, L.; CHEN, Z.; LIN, Y.; XU, K.; CHEN, G.Q. Synthesis, characterization and biocompatibility of biodegradable elastomeric poly(ether-ester urethane)s based on poly(3-hydroxybutyrate-co-3-hydroxyhexanoate) and Poly(ethylene glycol) via melting polymerization. $J$. Biomater. Sci. Polym. Ed., v.20, n.9, p.1179-1202, 2009.

MAKADIA, H.K.; SIEGEL, S.J. Poly Lactic-co-Glycolic Acid (PLGA) as biodegradable controlled drug delivery carrier. Polymers (Basel), v.3, n.3, p.1377-1397, 2011.

MOHAMADNIA, Z.; AHMADI, E.; RAFIENIA, M.; MIRZADEH, H.; MOBEDI, H. Investigation of drug release and $1 \mathrm{H}-\mathrm{NMR}$ analysis of the in situ forming systems based on poly(lactide-co-glycolide). Polym. Adv. Technol., v.20, n.1, p.48-57, 2009.

O R O Z C O - C A S T E L L A N O S, L.M .; M A R C O S FERNÁNDEZ, A.; MARTÍNEZ-RICHA, A. Hydrolytic degradation of poly( $\varepsilon$-caprolactone) with different end groups and poly( $\varepsilon$-caprolactone-co- $\gamma$-butyrolactone): characterization and kinetics of hydrocortisone delivery. Polymer. Adv. Tech., v.22, n.4, p.430-436, 2011.
PARK, S.J.; KIM, K.S.; KIM, S.H. Effect of poly(ethylene oxide) on the release behaviors of poly(epsiloncaprolactone) microcapsules containing erythromycin. Colloids Surf., B, v.43, n.3/4, p.238-244, 2005.

REDDY, T.T.; KANO, A.; MARUYAMA, A.; TAKAHARA, A. Synthesis, characterization and drug release of biocompatible/biodegradable non-toxic poly(urethane urea)s based on poly( $\varepsilon$-caprolactone)s and lysine-based diisocyanate. J. Biomater. Sci. Polym. Ed., v.21, n.11, p.1483-1502, 2010.

RITGER, P.L.; PEPPAS, N.A. A simple equation for description of solute release I. Fickian and non-fickian release from non-swellable devices in the form of slabs, spheres, cylinders or discs. J. Control. Release, v.5, n.1, p.23-36, 1987a.

RITGER, P.L.; PEPPAS, N.A. A simple equation for description of solute release II. Fickian and anomalous release from swellable devices. J. Control. Release, v.5, n.1, p.37-42, $1987 b$.

SIEPMANN, J.; SIEPMANN, F. Modeling of diffusion controlled drug delivery. J. Control. Release, v.161, n.2, p.351-362, 2012.

SIVAK, W.N., POLLACK, I.F., PETOUD, S., ZAMBONI, W.C., ZHANG, J., BECKMAN, E.J. LDI-glycerol polyurethane implants exhibit controlled release of DB-67 and anti-tumor activity in vitro against malignant gliomas. Acta Biomaterialia, v.4, n.4, p.852-862, 2008.

SKARJA, G.A.; WOODHOUSE, K.A. Synthesis and characterization of degradable polyurethane elastomers containing an amino-acid based chain extender. J. Biomater. Sci. Polym. Ed., v.9, n.3, p.271-295, 1998.

STOREY, R.F.; WIGGINS, J.S.; PUCKETT, A.D. Hydrolizable poly(ester-urethane) networks lfrom L-lysine diisocyanate and D,L-Lactide/E-caprolactone homo- and copolyestertriols. J. Polym. Sci. A Polym. Chem., v.32, n.12, p.2345-2362, 1994. 
VERSTRAETE, G.; MERTENS, P.; GRYMONPRÉ, W.; VAN BOCKSTAL, P.J.; DE BEER, T.; BOONE, M.N.; VAN HOOREBEKE, L.; REMON, J.P.; VERVAET, C. A comparative study between melt granulation/ compression and hot melt extrusion/injection molding for the manufacturing of oral sustained release thermoplastic polyurethane matrices. Int. J. Pharm., v.513, n.1/2, p.602$611,2016$.

Received for publication on $26^{\text {th }}$ July 2016 Accepted for publication on $16^{\text {th }}$ November 2016 